\title{
Brincar de gênero, uma conversa com Berenice Bento*
}

\section{Diego Madi Dias**}

O trabalho de Berenice Bento é uma referência incontornável para os estudos recentes de gênero no campo das ciências sociais. Seu livro A reinvenção do corpo: sexualidade e gênero na experiência transexual, publicado em 2006 pela editora Garamond, foi para mim uma porta de entrada para o tema da transexualidade - assunto que eu procurava compreender melhor naquele ano de 2011, quando iniciava o meu doutoramento em antropologia pela Universidade Federal do Rio de Janeiro.

Em julho de 2012, assisti a Berenice falar na ocasião da fundação da ABHT - Associação Brasileira de Homens Trans*1, em São Paulo. Conhecemo-nos em dezembro do mesmo ano, quando Berenice se apresentou no evento "UFRJ para Todxs", no campus da Praia Vermelha, no Rio de Janeiro. Mantivemos contato e então nos encontramos novamente no início de 2013, dessa vez em Paris, onde Berenice estava desenvolvendo uma pesquisa comparativa e eu realizava meu estágio de doutorado. Durante os dias que estivemos juntos em Paris, conversamos muito sobre questões teóricas e questões práticas de conjuntura

\footnotetext{
* Recebida para publicação em 25 de outubro de 2013, aceita em 21 de agosto de 2014. Agradeço à professora Berenice Bento por sua generosidade em ceder essa entrevista e também por sua atenção aos meus próprios dados e interesses de pesquisa.

** Doutorando no Programa de pós-graduação em Sociologia e Antropologia da Universidade Federal do Rio de Janeiro - PPGSA/ UFRJ. diegomadias@gmail.com 1 O uso do asterisco tem por objetivo indicar um "termo guarda-chuva" (umbrella term) que se refere a diversas experiências de gênero não normativas, tais como transexual, transgênero ou travesti. Como se tornará claro, esse uso está de acordo com a perspectiva desenvolvida pela entrevistada, cujo trabalho contribuiu para o questionamento da ideia de um sujeito transexual universal.
} 
envolvendo direitos civis relacionados a gênero e sexualidade. Participamos orgulhosos de uma grande manifestação pelo casamento para todos (le mariage pour tous), matéria de acalorado debate na França naquele momento.

Possivelmente a primeira voz a ecoar dentro da academia em favor da despatologização das identidades trans*, Berenice propõe uma articulação entre o pensamento acadêmico e a agenda política que informa de modo decisivo tanto a sua produção intelectual de conhecimento quanto as atividades que coordena no contexto da Universidade Federal do Rio Grande do Norte, no Núcleo Interdisciplinar Tirésias ${ }^{2}$.

Nossa conversa foi gravada em um café na região do Marais, em Paris, no dia $1^{\circ}$ de fevereiro de 2013. Procurei desenvolver aqui alguns dos questionamentos que me foram proporcionados pela leitura do livro de Berenice e pelas diferentes ocasióes em que eu pude escutá-la publicamente.

Diego Madi: Eu gostaria de começar dizendo que considero o seu trabalho fundamental para o campo brasileiro dos estudos de gênero. Seu trabalho proporciona inspirações, políticas e teóricas, que parecem cruciais para o contexto contemporâneo no qual se desenvolvem as discussões sobre gênero e sexualidade. A inspiração teórica tem a ver com o mérito de ter trazido para o ambiente acadêmico de língua portuguesa a força das teorias performativas de gênero. Como você sabe, há ainda pouca coisa traduzida ou produzida a partir dessas perspectivas, que podemos considerar recentes. Em um sentido político, sua etnografia demonstra que os processos de (re)designação de gênero estão nas mãos de um segmento social específico, um grupo que detém o poder-saber de legitimar o que é a "natureza normal do corpo sexuado" a partir de uma suposta neutralidade científica. Estou falando do biopoder, da biopolítica exercida pelos discursos médicos e suas instituições correspondentes. Nesse sentido, o seu

$2<$ http://www.nucleotiresias.ufrn.br/> 
trabalho deve ser lido como uma defesa pela despatologização das identidades trans*.

Sobre as influências das teorias performativas de gênero, de uma maneira geral, e o pensamento de Judith Butler, de uma maneira mais específica, como isso apareceu nas suas reflexões? Como isso aconteceu na sua trajetória de pesquisa?

Berenice Bento: Como eu construo as minhas pesquisas? Eu tenho uma questão, um problema sociológico, começo a ler e a elaborar problemas, mas acho importante deixar que o campo possa conduzir. Eu deixo que a pesquisa empírica me envolva $e$ mostre os caminhos. Se, em um primeiro momento, eu tenho um problema sociológico e vou para o campo com determinadas questóes, em um segundo momento é o próprio campo que me diz a direção em que eu devo seguir. Isso foi muito forte na minha pesquisa para a tese de doutorado. Eu diria que seriam duas teses, na verdade. Inicialmente, comecei o trabalho de campo em um hospital que realizava as cirurgias de transgenitalização. Naquele momento, entre os anos de 1999 e 2001, eu estava totalmente orientada por uma literatura médica/psi patologizante. Penso que talvez o mérito do meu trabalho tenha sido justamente esse a que você se referiu. Foi a primeira tese ancorada na teoria queer no Brasil. Foi a primeira tese a trabalhar com o pensamento de Beatriz Preciado e Judith Butler. Eu devo muito também ao pensamento de Jack Halberstam e Del LaGrace Volcano, por exemplo. Mas por que essas ideias foram tão importantes para mim? Quando eu fazia campo no hospital, tudo o que eu lia me dizia que aquelas pessoas sofriam de um transtorno de identidade de gênero ou eram disfóricas. Algumas referências trabalhavam com a ideia de "transexualismo". Mas eu não conseguia ver isso, eu podia ver jogos, negociações. Eu ficava no hospital, mas eu também precisei sair do hospital... fui à casa das meninas, eu fui para o shopping, vi como elas se arrumavam. Enquanto para muita gente é terrível estar em um hospital, inclusive para as pessoas trans* que precisam se submeter a um protocolo absurdo, havia algo diferente ali: elas colocavam a melhor roupa para ir ao 
hospital. Chegavam perfumadas, maquiadas. Era estranho ver aquelas mulheres vaidosas, bonitas, no ambiente absolutamente decadente do hospital. Não combinava. Eu me perguntava como aquilo era possível. Ao mesmo tempo, elas estavam reproduzindo um discurso totalmente marcado pela ideia de uma identidade feminina hegemônica: subalternidade, passividade. E no caso dos homens trans* era visível o discurso que valorizava a virilidade. Mas quando eu ia às suas casas, aqueles discursos proferidos no ambiente do hospital ficavam sem sentido. Elas trabalhavam, se sustentavam e, em alguns casos, também sustentavam seus maridos. No caso dos homens trans*, a virilidade discursiva dava lugar a homens que compartilhavam as tarefas domésticas $e$ performatizavam uma masculinidade sensível. Não se encaixavam o que eles e elas diziam e a prática. Concordo com Scott (1999), quando afirma que os discursos não autoevidenciam as experiências. O próprio discurso é uma experiência singular. Era muito importante a centralidade que o hospital tinha naquele momento das minhas primeiras formulações. Eu entendia o hospital como um rito de passagem. Você é antropólogo e sabe o caráter iniciático de um rito de passagem. Ele definirá um "antes" e um "depois". Mas eu estava errada, era uma bobagem essa minha hipótese! O hospital não é "rito de passagem". O hospital era um lugar de negociações, de tensão, e principalmente de relações de poder. Essa minha primeira hipótese sobre a ideia de um rito de passagem foi sendo desconstruída, problematizada $e$ mesmo negada ao longo do meu trabalho de campo. Quando eu fui para a Espanha, depois que eu concluí meu campo aqui no Brasil, o meu olhar sobre os corpos transexuais era também patologizante. Eu observava uma pessoa trans* que chegava em uma reunião do coletivo em que eu estava pesquisando/atuando $e$ se ela usasse um jeans e não escondesse o pênis, ou se portasse roupas masculinas, se tivesse barba e mesmo assim dissesse: "meu nome é Natália", eu pensava: "jamais! Não é trans*. É um homem, um homossexual, um homem que não está querendo assumir a sua homossexualidade". Veja como o meu olhar foi construído por esse espaço do hospital também. São muitos 
movimentos: a subjetividade da pesquisadora olhando para o campo e refletindo sobre ele, reconstruindo os "objetos" de sua pesquisa (entre aspas, porque não existem objetos de estudos nas ciências sociais), e eu fui percebendo isso apenas com o passar do tempo, quando eu comecei a me questionar "então, o que significa ser uma mulher ou ser um homem de verdade?" porque a discussão sobre a verdade, sobre a mentira, sobre a cópia, mímesis e origem... todas essas discussões estavam diante de mim. Foi no ativismo espanhol, então, fora do espaço da clínica, que eu pude realmente entender e problematizar a ideia de uma identidade essencial, pensar que ninguém tem "gênero". Fazemos gênero o tempo inteiro, somos fazedores de gênero. E isso tudo foi acontecendo justamente quando eu tive um encontro com a teoria queer, entre 2001 e 2002. Preciado tinha acabado de lançar o Manifiesto Contra-Sexual (2002) na Espanha. Eu li também Problemas de Gênero (Butler, 2001), o manifesto do Del LaGrace Volcano (Halberstam \& Volcano, 1999). Assisti a uma bela conferência de Jack Halberstam também nesse ano, em Castellon. Tudo era novidade: o coletivo trans* de Valência/Espanha começava se estruturar, o projeto de lei de identidade de gênero também começava a ser debatido de forma mais intensa (e só foi aprovado em 2007), os primeiros textos queer começavam a ser traduzidos na Espanha... Com o tempo, fui vendo que aquela teoria me servia, principalmente a dimensão performática do gênero. Foucault está certo: temos que usar uma teoria se ela nos serve para alguma coisa. Se não serve, devemos deixá-la de fora! Os textos da Butler, principalmente, conseguiram me dar um aporte explicativo para interpretar os processos de organização das múltiplas subjetividades e identidades trans*. Eu acredito que o grande mérito da minha tese foi o de, há quase 15 anos, falar em despatologização. Já nas primeiras linhas eu anunciei o meu desejo de que aquelas reflexões contribuíssem para despatologizar identidades. Claro que essas concepções estão longe de qualquer consenso, inclusive entre parcelas consideráveis de pessoas que vivem as experiências trans*. Portanto, tentei contribuir para instaurar uma disputa teórica, afirmando a necessidade de discutir 
o que é normal e o que é patológico, no âmbito do gênero, algo inusitado nas reflexões feministas no Brasil.

DM: Parece-me bastante interessante o movimento que você empreende da experiência transexual, de forma localizada, para os processos de construção de gênero de uma maneira mais ampla, como se fosse mesmo uma lição que devemos aprender a partir da experiência trans*, que torna claros os processos sociais performativos de construção e "normalização" de gênero. Aí problematizamos a própria questão do que significa ser homem $e$ mulher, como você expressou tão bem em sua apresentação no dia da fundação da ABHT. Você falava do gênero como um mecanismo de constrangimento e opressão que opera por meio da produção de corpos inteligíveis, corpos que precisam corresponder a uma estética de gênero. Gostaria que você comentasse sobre isso.

BB: A questão da transexualidade me interessa como pensadora das relações de gênero, sem dúvidas. Mas há uma questão política: a população trans* é uma população extremamente vulnerável e desumanizada. Após fazer trabalho de campo com uma população que enfrenta esses níveis de exclusão social, seria impossível que eu não me sensibilizasse e não me tornasse uma pessoa politicamente engajada. Mas, de fato, gostaria de ressaltar que eu faço política desde os meus 15 anos. A minha geração, a dos 1980, lutou apaixonadamente pelo fim da ditadura e pela reconstrução das instituições democráticas. Esse é outro belo capítulo da vida política nacional. Eu não descobri a política fazendo a minha tese, mas passei a ver outras dimensões da política que antes eram invisíveis para mim. Mas a questão da transexualidade me interessa por outro motivo: nenhuma outra experiência de gênero é tão forte no sentido de desnaturalizar o que é ser homem e o que é ser mulher. As feministas mais históricas deveriam agradecer pelas reivindicações das mulheres $e$ homens trans*. Uma concepção de gênero que pensa que o masculino $e$ o feminino são os significados culturais que as sociedades atribuem à diferença sexual reafirma a naturalização. Além de uma desnaturalização limitada, e aqui penso no livro $O$ 
Segundo Sexo (Beauvoir, 1970), uma concepção de gênero fundada na diferença sexual como princípio estruturante das performances de gênero, não alcança o debate sobre o caráter político da sexualidade. E aí nos restam duas alternativas para analisar as experiências trans*: ou as interpretamos como uma patologia, e o passo seguinte será a sua universalização - porque, se é uma patologia, os indicadores vão se repetir em todos os lugares do mundo; ou então relativizamos, e aí compreendemos que existem muitas possibilidades de viver as transexualidades, $e$ como corolário imediato teremos os deslocamentos das noções de masculinidade e feminilidade de qualquer referente biológico. Nosso léxico é extremamente pobre e binário. O que chamamos de masculinidade talvez pudesse ter outro nome. Determinadas concepções feministas, ainda hegemônicas em larga medida, identificam o masculino como um atributo do homem $e$ a feminilidade como um atributo da mulher. Se você entende que ninguém nasce homem e ninguém nasce mulher, e radicaliza essa perspectiva, não faz mais sentido discutir a legitimidade da demanda de sujeitos que querem reconstruir o seu gênero socialmente. Há outra questão que me interessa e que me preocupa: existe hoje uma discussão interna ao movimento trans* sobre a despatologização, é uma discussão pontual sobre a necessidade da retirada da transexualidade do CID - Código Internacional de Doenças (que está em processo de revisão) $-e$ do DSM - Manual Estatístico de Transtornos Mentais da Associação de Psiquiatria Norte-Americana (APA). A APA já publicou sua nova versão e alterou a tipificação de Transtorno de Identidade de Gênero (na qual estavam incluídas as pessoas trans* nas diversas fases da vida - infância, adolescência e fase adulta), e agora o diagnóstico que os psiquiatras nortesamericanos farão será de Disforia de Gênero. Ainda estamos na expectativa pela nova versão do CID. Há, portanto, dois documentos que são centrais, referências no mundo das biociências e das ciências psi, que definem as expressões de gênero que fogem do binarismo como transtorno. E há uma discussão interna ao movimento no sentido de que a 
despatologização provavelmente prejudique o acesso das pessoas trans* às cirurgias. E aqui gostaria de apontar uma dimensão desse debate que é pouco discutida. Eu não acho que a despatologização diga respeito às pessoas trans* exclusivamente. Diz respeito a todos/as, especialmente aos homossexuais. Dizem que a homossexualidade foi retirada do CID. É verdade, mas aconteceu a patologização do gênero. No caso de um menino que brinca de boneca e seu pai consulta um especialista para "tratar" esse comportamento, psicólogos ou psiquiatras não podem mais "diagnosticar" a homossexualidade porque a homossexualidade não consta no CID, mas podem diagnosticar a disforia de gênero ou transtorno de identidade de gênero. Ou seja, a armadilha é simples. Hegemonicamente, o sexo não está desvinculado do gênero, ou seja, quando eu digo "sou mulher" esse enunciado explicita a minha sexualidade, a heterossexualidade. Gênero e sexualidade são apresentados como identidades essenciais e uma dimensão identitária só existe quando é referenciada na outra. Aquilo que foge a essa identidade essencial deve ser entendido como um transtorno. O gênero, portanto, de uma categoria cultural passou a ser uma categoria diagnóstica. Setores do feminismo se calam diante dessa realidade. Os gays também se calam. "Nós, gays, lésbicas não somos mais patologizados!". Não é verdade. Os pais continuam levando seus/suas filhos/filhas para serem "tratados/as" nas clínicas e nos consultórios. Diagnosticar como homossexual não pode, mas diagnosticar como transtorno de identidade de gênero é legalmente possível? E por que os pais procuram a ajuda de profissionais? Seria porque suas filhas não gostam de brincar de bonecas? É só isso? É o fantasma da homossexualidade. Então, o que me interessa na questão da despatologização, para além das questões específicas às pessoas trans*, é pensar outra ordem de gênero. É pensar que essa ordem binária, naturalizada e naturalizante, não oprime as pessoas trans* exclusivamente, oprime a mim e a você também. 
DM: Dada a necessidade evidente de produzirmos caminhos, soluções e políticas para que essa questão deixe de produzir opressão, violência e até a morte, o que se pode ou se deve fazer?

BB: A solução mais imediata seria aceitar que as pessoas trans* pudessem fazer a cirurgia de transgenitalização, que o Estado pagasse, que pudessem mudar legalmente suas identidades de gênero (quantos vezes quisessem), que eu pudesse chegar em minha escola vestida "de menino" e performatizando a masculinidade e ninguém estranhasse. Mas essas não são ainda soluções definitivas. Eu acho que é preciso empreender uma luta pelo fim do gênero, no sentido binário e naturalizado que vigora hoje. O gênero é daqueles marcadores da diferença que produz opressão. Veja, não estou falando em acabar com a ideia de gênero, mas se eu não tenho obrigação de corresponder a um estereótipo de gênero, e se eu posso "brincar de gênero", qual o problema? É isso o que as crianças fazem: brincam de gênero $e$ sofrem toda a força das normas para capturá-las. O livro $O$ menino que brincava de ser (Martins, 2008) narra a história de um garoto que gostava de brincar de faz de conta e nesse espaço mágico ele encarnava uma bruxa, outras vezes Peter Pan, para o desespero dos pais. Deixem as crianças brincarem livremente! Provavelmente, veremos uma grande liberdade de composição $e$ fantasias. Portanto, devemos lutar pela abolição do gênero, esvaziá-lo do seu caráter opressor. Essa luta, a meu ver, dialoga intensamente com a experiência histórica da luta pelo fim do racismo e da escravidão. Embora saibamos que a cor da pele é um operador para distribuição dos corpos na estratificação social, um discurso claramente racista atualmente é punido como crime. Quando penso na abolição do gênero, penso em ficarmos com a dimensão da fluidez e combater as supostas determinações biológicas para explicação de nossas subjetividades e desejos. Isso pode nos colocar diante de novos desafios para pensarmos que, nesse contexto, não terá muito sentido falarmos de identidade de gênero. Da mesma forma como se defendia que a cor da pele predispunha as pessoas a pensarem e agirem de determinada 
maneira (claro, para dizer que os/as negros/as não pensavam). Ora, o que é uma identidade de gênero? Uma forma de sentir/viver o mundo como homem e como mulher? $\mathrm{O}$ que é um campo emotivo feminino ou masculino? É um jeito de atuar na vida? Se tensionarmos, torcermos, contorcermos a noção de gênero e de identidade de gênero, veremos que essa categoria tem cumprido o mesmo papel da noção de raça: produção incessante de hierarquias assimétricas e desiguais.

Continuando com a imagem de gênero e fantasia/brincadeira, quando crescemos, não paramos de brincar de gênero, principalmente, no âmbito do desejo. Uma das maiores fontes de prazer é a realização de jogos sexuais generificados. $\mathrm{O}$ fato de um homem ter prazer em uma calcinha, cinta-liga, nos revela outra possibilidade do que estou chamando de brincar de gênero. Ele é gay? A pobreza de uma concepção identitária provavelmente não suporta pensar que uma mulher na cama possa colocar uma cinta, com um pênis de plástico e penetrar seu companheiro, e que eles possam se deliciar nos jogos e fantasias de gênero. A cama também pode ser o nosso parque de diversões. A crença nas linhas de continuidade entre sexualidade-gênero é uma estrutura estruturante dos discursos normatizadores da vida. Mas sexualidade e gênero não têm nenhuma linha de continuidade. E a anunciação performática e precária "eu sou mulher" nada revela de minha/nossa/sua sexualidade.

Mas voltando à sua pergunta: é sempre complicado falar em uma "solução". Porque não há uma solução, há caminhos, há disputas, há discussões... Eu acho que cada sociedade encontra seus próprios caminhos para lidar com essas questões, os movimentos sociais têm também dinâmicas próprias em diferentes partes do mundo. No Brasil, eu acho que os movimentos sociais são muito institucionalizados. $\mathrm{O}$ contexto brasileiro é muito interessante para pensar, especialmente com a vitória do PT nas três últimas eleições. Essa militância que estava no movimento LGBT era filiada a um partido. O movimento LGBT não foi capaz de produzir a autonomia necessária para se constituir como um sujeito político independente e formar um campo de disputa 
contra-hegemônico. Ao contrário, eu afirmaria que foi assimilado pelo Estado. No Brasil, é muito forte a partidarização dos movimentos sociais. E eu questiono se devemos buscar um caminho exclusivamente por meio dos movimentos sociais institucionalizados. É uma pergunta para a qual eu não tenho a resposta. Penso em políticas públicas, em movimentos culturais, nas produções cinematográficas, nas artes plásticas e atividades culturais em geral, no papel das universidades. São muitos os caminhos por meio dos quais podemos problematizar $e$ desconstruir o gênero.

DM: É muito interessante a sua reflexão sobre as "brincadeiras de gênero". Isso porque começamos a ter notícias de situações que expressam um ideal pós-gênero, mas talvez seja utópico querer acabar com o gênero na língua e nas coisas. Estaríamos então falando em "nos apropriar" das convenções de gênero ao invés de querer acabar com elas ou de simplesmente nos submeter a elas. É isso mesmo?

BB: Para que serve gênero? O gênero serve para construir corpos, é uma máquina de produção em série de seres humanos. Se você tem pênis, é homem; se tem vagina, é mulher. Em ambos os casos você deve ser heterossexual. $\mathrm{E}$ há então um conjunto de dispositivos linguísticos, médicos, religiosos... que se organiza e se estrutura a partir de uma engrenagem bastante complexa para produzir uma afirmação sobre o ser: "eu sou uma mulher". Essa afirmação tem uma força impressionante. O que significa alguém afirmar isso? "Eu sou uma mulher" e, portanto, "eu não sou um homem". Se consideramos que esse sistema de gênero não serve, pois produz exclusão e sofrimento, o que devemos fazer? Nós temos alguma coisa que chamamos de gênero e algo novo só poderá ser produzido a partir desse velho esquema conceitual. O que vem depois, eu realmente não sei. $\mathrm{O}$ que temos hoje não serve. Como seria uma era pós-gênero, como seria o gênero, eu não sei. As coisas têm nomes, há coisas de meninos e coisas de meninas. Mas se o menino quer brincar com coisas de meninas, qual o problema? Estamos ainda no campo das demarcações. Eu 
não sei se poderíamos falar em pós-gênero. Talvez fosse melhor falar em um conceito de gênero renovado. Eu proponho a ideia de "libertar o conceito de gênero do biopoder". Mas não é simples, é complicado. O gênero é um elemento que fundamenta a política do Estado. Os temas relacionados às populações são sempre tratados em função da ideia do masculino/homem e feminino/mulher. $\mathrm{O}$ Estado moderno dá centralidade à noção de gênero no desenvolvimento de suas políticas, assim como fez com raça até pouco tempo. Isso porque para que tenhamos um Estado, precisamos ter uma "população" que corresponda a esse Estado, além do território e do idioma. Sem população, não há Estado. Em uma perspectiva biopolítica, a questão do gênero é realmente central. Quando falamos sobre as relações de poder, quando sugerimos que gênero não deve ser um assunto da medicina, quando defendemos o radical direito à autodeterminação de gênero, estamos buscando libertar o gênero do biopoder. Gênero é hoje um assunto de Estado. Ao produzir as identidades de homem e mulher com base na biologia, estamos produzindo identidades de gênero a partir de um processo extremamente violento, que está vinculado à produção de identidades sexuais. A produção do sujeito no mundo segue um protocolo de gênero $e$ de sexualidade. Falamos sobre a ideia de inteligibilidade. Dizem que eu sou mulher, eu não faço a menor ideia do porquê. Eu sou um homem. Dentro daquilo que definem como sendo um homem, eu sou um homem. Eu não sou mulher. Eu sou mulher porque eu me visto como mulher? Mas a minha subjetividade é totalmente masculina, dentro do binarismo que circula por aí. Outro dia, eu respondi a um desses testes que circulam na internet para descobrir o gênero do meu cérebro. Resultado: meu cérebro é $100 \%$ masculino!! Eu morri de rir. Ou seja, os cromossomos estão em baixa na medicina. A moda agora é falar de cérebro e hormônios. Os $\mathrm{XX}$ e $\mathrm{XY}$ ficarão como um registro de uma medicina atrasada do século XX. Por que sou homem? Porque tenho atributos masculinos: decisão, fazer, realizar, racionalidade. $\mathrm{O}$ que eu tenho de mulher? Nada. Ter um útero é suficiente para 
me definir como mulher? Eu dou esse útero de presente, você quer? Eu não quero.

Sobre o que virá depois, eu realmente não sei, eu estou muito preocupada com o que está acontecendo agora, diante da gente. O espaço da escola é totalmente demarcado pela questão de gênero: o banheiro, o prato em que as crianças comem. Eu dei um curso de formação para professores do ciclo básico e, em uma dessas ocasiões, uma professora contou que um aluno, na hora da refeição, não queria comer porque os pratos azuis estavam todos ocupados. E ele não podia comer em prato rosa. Uma criança de três ou quatro anos. Se ele comesse em um prato rosa iriam dizer que ele é bicha. Eu perguntei à professora o que fizeram: "demos um jeito e conseguimos um prato branco".

DM: Sobre as demandas da população trans*, eu me lembro da sua apresentação no encontro "UFRJ para todxs", em que você chamou a atenção pela primeira vez ao que pode estar acontecendo de um "jeitinho brasileiro", talvez um modo de lidar com os impasses legislativos para a conquista de direitos, uma vez que temos um Congresso povoado por grupos conservadores. Estou falando das resoluções normativas. Você poderia retomar esse ponto e explicar seu ponto de vista, incluindo a experiência da UFRN?

BB: A experiência da UFRN é uma experiência como outras dezenas no Brasil. Naquela ocasião, eu estava preparando um roteiro para a minha apresentação e comecei a ler as normatizações sobre o nome social nas universidades brasileiras. Eu pensei: "olha o que está diante da gente e não estamos percebendo". Nessa semana, o Ministério da Saúde, em um ato solene, na presença da Fernanda Benvenutty, uma grande líder do movimento trans* no Brasil, definiu que a partir de agora as pessoas trans* teriam direito ao uso do nome social na carteira do SUS. O Estado está reconhecendo a identidade de gênero sem existir nenhum protocolo. Uma pessoa que procure o SUS $e$ apresente sua carteira com o nome social não vai precisar passar por nenhum protocolo. É autodefinição de gênero. O Estado 
brasileiro está fazendo isso, o Executivo. O que está acontecendo no Brasil é uma coisa muito estranha, é verdade, mas precisamos nos utilizar disso como argumento. Alguns dizem que não podemos despatologizar porque senão o SUS não vai arcar com a saúde das pessoas trans*, principalmente as cirurgias. Chegou-se ao ponto de negociar a própria condição de sujeito. A patologização significa que você tem que seguir protocolos $e$ alguém precisa assinar um documento atestando que você é o que você afirma ser. No campo da saúde, você é transtornado. É muita contradição. O Ministério da Saúde fornece uma carteira em que reconhece sua identidade de gênero, sem perguntar nada sobre a cirurgia, sem perguntar se a pessoa passou ou quer passar por cirurgia, simplesmente reconhece. Nas universidades acontece a mesma coisa. Por que então eu preciso de um protocolo para alterar meus documentos oficiais de identificação? O que temos é um grande paradoxo. Estamos no campo das contradições $e$ vivemos em um mundo de contradições. Eu sempre fui muito crítica às Portarias porque elas não resolvem nada definitivamente. Mas como o Estado pode reconhecer, por um lado, a minha autonomia para definir minha identidade de gênero e, por outro lado, não a reconhecer?

DM: Isso indica um avanço?

BB: Isso indica um paradoxo que não estamos sabendo explorar. Talvez devêssemos provocar o STF - Supremo Tribunal Federal para que reconheça a identidade de gênero.

DM: Você sugere que se utilizem os casos do SUS e das universidades como jurisprudências para outras esferas?

BB: Exatamente. Temos decisões acumuladas no Brasil em um nível suficiente, de modo que não faz mais sentido exigir que uma pessoa tenha que se submeter a protocolos médicos para alterar sua identidade.

DM: E esse processo legislativo é muito diferente na Espanha? Onde encontramos uma situação mais próxima do ideal? 
BB: Em 2007, a Espanha aprovou uma lei que estabelece a necessidade de um parecer, um diagnóstico, um relatório médico. Mas não há necessidade de cirurgia para solicitar mudança de nome. Há médicos que podem exigir dois anos de acompanhamento, mas há outros médicos que em poucas sessões podem fornecer um atestado de transtorno de gênero. Na Argentina, não. Você vai ao cartório e muda seus documentos sem nenhum outro documento anterior que esteja dizendo que você é o que você é. Eu entrevistei o Miguel Missé, que é um dos organizadores do livro El Género Desordenado (Missé \& CollPlanas, 2011), um livro sobre despatologização. Ele me disse que a lei espanhola era um avanço, sem dúvidas, mas que no dia seguinte à sua aprovação foi iniciado um movimento pela despatologização. Veja só: nós sempre falamos em consciência de classe, consciência ecológica, talvez devêssemos falar em consciência de gênero. É um problema ter que se submeter aos médicos e solicitar um parecer para que se possa alterar seu próprio nome. Miguel me falou que tinha o parecer necessário para dar início ao processo de alteração dos documentos, mas que ele não iria mudar seu nome enquanto o Estado espanhol não reconhecesse seu pleno direito de migrar de um gênero para outro, quantas vezes ele quisesse. A Argentina hoje seria a vanguarda no que diz respeito a uma lei de identidade de gênero.

DM: Gostaria de saber sua opinião sobre a importância de investimento em materiais pedagógicos. Tivemos o caso do veto da presidente Dilma aos vídeos do chamado "kit gay" e você realizou uma ação importante de exibição e discussão desses vídeos na UFRN através do núcleo Tirésias.

BB: O Estado brasileiro precisa entender o que é violência de gênero, o que é homofobia, o que é transfobia. Os gestores públicos precisam se formar. Precisamos de políticas públicas. Não basta fazermos cursos de formação para os professores dos ciclos fundamental e básico. É algo frustrante, muito duro. É difícil produzir uma fissura nesse pensamento que está tão naturalizado. "Aquilo existe desde sempre". "Foi Deus quem fez". Vou te contar 
uma "técnica" que utilizamos, nós do Núcleo Interdisciplinar Tirésias, quando fazemos cursos para adolescentes. Em determinado momento, perguntamos: "Tem algum heterossexual na sala? Por favor, levante a mão quem se considera heterossexual". O silêncio é total. Raramente algum estudante levanta a mão. Logo depois, afirmamos: "Genial, nesta escola só temos gays e lésbicas. Que maravilha! Uma escola vanguarda!". Nesse momento, inevitavelmente, eles/as gritam: "não!! Eu não sou bicha!!! Eu não sou sapatão!!!”. Essa experiência pode ser lida e interpretada de várias maneiras. Lembro-me, reiteradamente, do verso de Fernando Pessoa: "Os deuses são deuses porque não se pensam". O que esse exercício nos revela é que a naturalização da heterossexualidade é de tal ordem, que ninguém pensa sobre os processos a que foram submetidos para a produção dessa verdade última: os corpos são heterossexuais.

Voltando à sua pergunta: eu escrevi um artigo de opinião sobre o veto da presidenta. A homofobia e a misoginia têm entrado como ponto de negociação nas campanhas eleitorais no Brasil, municipais, estaduais e federais. Em uma disputa interna no Senado, a bancada evangélica simplesmente negociou a retirada de um material que estava pronto $e$ foi pensado por mais de dois anos. E então a presidenta declarou que o Estado não deve se envolver em questões privadas. Isso vai contra tudo o que o movimento feminista formulou e formula há décadas. Foi devido à politização do espaço privado que hoje temos a lei Maria da Penha. Um pai e uma mãe não têm direito de vida e de morte sobre o seu filho. $\mathrm{O}$ que a presidenta nos disse com essa declaração? Que se um menino é gay, e o pai não quer que ele seja gay, pode espancá-lo até que ele se torne heterossexual e isso é um problema da família. Que o Estado não deve interferir na intimidade e na privacidade das pessoas. $\mathrm{Na}$ universidade, reunimos o pessoal do Núcleo Interdisciplinar Tirésias; foram três dias de discussão e um abaixo-assinado; exibimos os vídeos como um ato de desobediência civil. Algumas pessoas defendiam que se tratou de um recuo estratégico da presidenta para garantir a governabilidade. Maldita governabilidade! Negocia-se tudo em 
nome desse pragmatismo que, a meu ver, tem feito a luta pelos Direitos Humanos no Brasil viver um profundo retrocesso. Não tenho nenhuma expectativa com o Governo Dilma. E acho que ainda teremos tempos piores.

DM: Algumas questões que abordamos até agora têm nos levado a um ponto recorrente: a transexualidade na infância. Como você disse, uma vez que não faz mais sentido curar a homossexualidade, a transexualidade teria assumido esse lugar de comportamento desviante a ser tratado. Isso poderia explicar o aumento de casos de transexualidade na infância?

BB: Sim, eu acredito que a emergência desses casos estão relacionados com a mesma matriz de medicalização das identidades. Há uma discussão muito grande sobre o desenvolvimento da sexualidade na infância, uma discussão muito orientada pela psicanálise. Eu penso que uma criança de quatro anos não sabe nada sobre sexualidade. Ela pode ter prazer em tocar sua genitália, da mesma maneira como tem prazer em comer uma comida. O que nós chamamos de sexualidade, o que inventamos como pertencendo ao domínio da sexualidade, para uma criança de seis anos isso não é sexualidade. Acho que utilizamos o mesmo nome (sexualidade) para coisas muito diferentes. Trata-se de um prazer em uma determinada parte do corpo. Também não podemos dizer que um menino de oito anos que gosta de "brincar" com outro menino é gay. De uma maneira geral, nós começamos a desenvolver nossas sexualidades por meio da homossexualidade. Eu brincava com as minhas amigas de pegar no peito, de mostrar e ver. Os meninos também, entre eles. Cristalizar a identidade de uma criança dizendo que ela é transexual na infância é bastante problemático. Essas propostas surgem como parte de um discurso progressista: "veja, estamos conseguindo compreender que um menino de oito anos que está brincando de boneca e quer vestir as roupas da mãe é transexual". Não! Estaríamos matando essa criança. As narrativas de meninas transexuais demonstram que o desejo pelo mundo do outro gênero aparece muito cedo, é verdade, mas a vontade de 
mudar o corpo aparece depois, na adolescência. Eu li um texto sobre uma criança de 8 anos que estava começando a tomar hormônios. "Isso é muito avançado"... Amigas minhas trans* falaram que isso é muito bom para a criança. Eu falei: "muito bom? Hormônios, com 8 anos?”. É a medicalização total. Acho que isso se insere em uma moldura mais ampla do que está acontecendo com a infância. Estamos diante da medicalização $e$ patologização da infância e, consequentemente, vemos a invenção de novas concepções de infância. Veja o sucesso da ritalina, a droga da concentração. A produção de corpos dóceis agora conta com ajuda de drogas. E acho que nesse contexto, oferecer hormônios para crianças é reforçar a mesma lógica binária do gênero e transformá-la em prisioneira de medicamentos. Eu não vejo isso como um avanço. É o contexto da medicalização das subjetividades e identidades.

DM: O grande problema, tanto do discurso médico que quer "corrigir", quanto do discurso progressista que quer "libertar", seria então acreditar que um ato precisa dizer alguma coisa do que aquela pessoa é. $\mathrm{E}$, ainda, que o quê essa pessoa é tem que ser definido e definitivo. A pessoa precisa se enquadrar em uma posição de gênero inteligível o mais rápido possível. É isso?

BB: Exatamente. Seja potencializando ou reprimindo os "excessos". De um jeito ou de outro estamos tratando de um conceito de "identidade essencial".

DM: Claro que não se trata aqui de fazer uma crítica aos pais. Deve ser difícil saber o que fazer. $O$ ideal seria que fôssemos menos obcecados com essa ideia de identidade e que deixássemos as coisas acontecerem...

BB: Os pais, angustiados, procuram os médicos. Se os médicos, com o poder que têm, dissessem assim: "fique tranquilo, isso é brincadeira de criança". Não temos médicos queers. Novamente cito o livro de Georgina (Martins, 2008). Os pais de Dudu o levam em vários médicos e todos repetem: seu filho é saudável, deixe-o brincar. Por fim, o endocrinologista aconselha os pais a 
procurarem ajuda para se livrarem dos preconceitos. Seria bom um médico queer que dissesse "isso não é importante, deixa ele brincar de boneca, se ele for pai um dia vai ser bom para esse menino treinar agora como cuidar de uma criança", como fizeram os profissionais que atenderam Dudu, o protagonista do livro de Georgina. O menino passou um batom: "qual o problema? Criança brinca mesmo". Imagine um médico que diga isso para os pais. Os pais poderiam mudar de médico ou então pensar "é mesmo?". Eu conheço relatos de diferentes países em que pais de crianças intersex, angustiados, conversam com um psicólogo sobre a possibilidade de cirurgia de "correção". E o psicólogo questiona se os pais têm certeza do que estão fazendo, se não querem esperar o filho crescer um pouco mais para decidir o que fazer.

DM: Ainda sobre a infância, no contexto dessa discussão atual acerca do "casamento para todos" aqui na França, especificamente na ocasião da manifestação contrária que ocorreu no dia 13 de Janeiro, os manifestantes reivindicavam justamente o "direito das crianças" a ter um pai e uma mãe. Essa era talvez a maior base argumentativa contrária ao casamento para todos: a proteção da infância. E então a Beatriz Preciado escreveu um lindo artigo, "quem defende a criança queer?" (Preciado, 2013), em que fala sobre o menino que gosta de se vestir de rosa, a menina que sonha em se casar com sua melhor amiga, enfim, em que fala sobre o direito das crianças de crescerem em um mundo sem violência de gênero, sem violência sexual, $e$ o direito das crianças a essa experimentação...

BB: É lindíssimo esse artigo de Beatriz Preciado, eu me emocionei profundamente. A infância é uma condição sobre a qual não se fala muito. O que as crianças e adolescentes sofrem nas escolas é uma verdadeira tortura psicológica. Não é coincidência que as pessoas trans* no Brasil sejam em grande parte analfabetas. Há alguma coisa nessa estrutura chamada "escola" que não suporta, que repulsa aqueles corpos. Mas eu não falaria em criança queer. Acho que o desafio é proteger a criança. Não existe criança queer, existem crianças. Nesse sentido, parece que Preciado comete um 
deslize na medida em que fala de uma identidade que já está pronta na infância: a criança queer. A demanda da criança é por amor, cuidado, proteção.

DM: Eu gostaria de perguntar também sobre a ideia de interseccionalidade. Você falou sobre as várias camadas de exclusão $e$ isso tem ficado cada vez mais claro nos estudos de gênero, ou seja: a necessidade de se pensar gênero, ou exclusão de gênero, de modo articulado com outros marcadores sociais de diferença.

BB: Perfeito. Gênero sozinho não explica nada, é uma categoria vazia.

DM: Eu acho importante o tratamento que você dispensa ao conceito de identidade: a partir dos seus dados, você demonstra que é problemático falar em um sujeito transexual universal. Como trabalhar com essa perspectiva interseccional sem correr o risco de fortalecer a produção de identidades baseadas em raça, classe etc.?

$\mathrm{BB}$ : $\mathrm{Eu}$ penso que a interseccionalidade rompe com essa possibilidade de se falar em um sujeito unicamente pela cor da sua pele, por exemplo. A raça/etnia não dá conta. Todos os determinismos de raça, de classe, de gênero, todos os determinismos caem por terra. Gênero, por exemplo, é uma categoria vazia. Se eu acho que entendo o que é ser homem e o que é ser mulher, ou seja, se eu penso que o gênero é capaz de dar conta da totalidade sobre o sujeito, eu estou então essencializando o gênero. Na questão da transexualidade, quando eu proponho a não existência de um sujeito transexual universal, são experiências múltiplas, localizadas, singulares. As jovens trans*, na reconstrução do corpo, enfrentam uma questão geracional muito interessante. A mulher-glamour dos anos 1970, siliconada, bundão, peitão, bocão... esse não é mais o modelo. As meninas trans* hoje em dia são mais enxutas, mais magras. Tem sim uma questão geracional; religiosa; de escolaridade. E a mesma coisa acontece com a homossexualidade. Ser gay é uma coisa como qualquer outra, que compõe a vida existencial de uma 
pessoa. Você pode ser antropólogo, gostar de determinado tipo de música, ser gay... uma pessoa é muitas coisas. Esses marcadores de diferença são fundamentais justamente em um movimento de desnaturalização, em que o olhar é orientado pela diferença e não pela igualdade. Quando você não trabalha com o pressuposto da identidade, você parte da ideia de que os sujeitos são diferentes $e$ têm apenas pontos provisórios de identificação, pontos de unidade que se juntam e se desfazem. Por isso que eu considero interessante a teoria do campo social, de Pierre Bourdieu (1996). Nós transitamos entre esses campos, o campo religioso, o campo econômico, o campo artístico. Podemos também utilizar a ideia de performance, conforme a sugestão de Erving Goffman (1985), a ideia de máscara. Trabalhar com a interseccionalidade proporciona um nível de complexidade nas análises antropológica e sociológica que é muito interessante. Uma coisa é ser trans* francesa e outra é ser trans* brasileira fazendo ponto no Bois de Boulogne $e^{3}$, podendo ser deportada a qualquer momento. É igual essa experiência? Essa caixinha chamada "mulheres trans*" agrupa pessoas que passam pelas mesmas experiências? Eu sou igual a uma mulher negra e favelada? Impossivel dizer que sim, não tem jeito.

DM: Para terminar, eu gostaria que você falasse sobre o seu livro que será publicado em breve, uma versão da sua dissertação de mestrado.

BB: Eu vou voltar ao Brasil e me dedicar imediatamente à revisão do texto. É um trabalho interessante. Eu estava no campo dos estudos de gênero em plena década de 1990, exatamente em 1995. Foi a primeira dissertação de mestrado no Brasil sobre masculinidades nas ciências sociais. Eu entrevistei homens $e$ mulheres residentes em Brasília, pertencentes à classe média urbana. Os trabalhos dos/as antropólogos/as do Museu Nacional foram importantes para mim. Eu escutava os homens falando e as demandas deles eram as mesmas das mulheres: eles queriam

${ }^{3}$ Parque público localizado no limite oeste do $16^{\circ}$ arrondissement de Paris. 
amor e cuidado. E também demandavam mulheres mais ousadas no mercado de trabalho, ao mesmo tempo em que admitiam não saber lidar com a autonomia sexual das mulheres. A partir das narrativas dos homens e das mulheres, eu concluí que estava diante de um considerável campo de intersecção subjetiva. Para me contrapor à suposta subjetividade binária dos gêneros, eu propus nomear essas novas configurações fundamentadas na ideologia igualitária, nos termos do Louis Dumont (1985), de "identidade comum de gênero". Muito antes da tese de doutorado, das discussões atuais, eu estava pensando em uma identidade comum aos gêneros no sentido de que se torna às vezes muito complicado marcar onde termina um gênero $e$ começa o outro. O campo foi feito com pessoas heterossexuais, mas a tensão estava ali.

DM: Você já estava preocupada com essa separação tão rígida entre homens e mulheres.

BB: Sim, totalmente. É uma dissertação sobre masculinidades e o título do livro é Homem não tece dor: queixas e perplexidades masculinas (Bento, 2012). No Brasil, esse tema era trabalhado basicamente por pesquisadores/as da psicologia social; nas ciências sociais, não havia produção. Eu acabei não publicando a dissertação, publiquei apenas um artigo e agora sairá na íntegra.

\section{Referências bibliográficas}

Beauvorr, Simone. O Segundo Sexo, vol. 1 - Fatos e Mitos. São Paulo, Difusão Europeia do Livro, 1970.

BENTO, Berenice. Homem não tece dor: queixas e perplexidades masculinas. Natal, EDUFRN, 2012.

BENTO, Berenice. A reinvenção do corpo: sexualidade e gênero na experiência transexual. Rio de Janeiro, Garamond, 2006.

BOURDIEU, Pierre. Razões Práticas: Sobre a teoria da ação. Campinas-SP, Papirus Editora, 1996. 
BUTLER, Judith. El gênero en disputa. El feminismo y la subversión de la identidad. México, Paidós, 2001.

DUMONT, Louis. O Individualismo - Uma perspectiva antropológica da Ideologia Moderna. Rio de Janeiro, Rocco, 1985.

GoffMAN, Erving. A Representação do Eu na vida cotidiana. PetrópolisRJ, Vozes, 1985.

HalBerstam, Judith "Jack" \& Volcano, Del LaGrace. The Drag King Book. Londres, Serpent'sTail, 1999.

MARTINS, Georgina da Costa. O menino que brincava de ser. São Paulo, Difusão Cultural do Livro, 2008.

MISSÉ, Miguel \&Coll-Planas, Gerald. El gênero desordenado: criticas em torno a la patologización de la transexualidad. Barcelona/Madrid, Egales, 2011.

PRECIADO, Beatriz. Qui défend l'enfant queer? Libération, 14.fev.2013.

PRECIADO, Beatriz. Manifiesto Contrasexual. Barcelona, Editorial Anagrama, 2002.

ScotT, Joan. Experiência. In: SILVA, Alcione Leite; SoUZA, Mara Coelho de Lago; RAMOS, Tânia Regina Oliveira (orgs.). Falas de Gênero: teorias, análises e leituras. Florianópolis-SC, Mulheres, 1999. 